\title{
Two-Dimensional Electrical Resistivity Investigation of Plants Roots and its Implication in University of Benin Engineering Field, Ugbowo, Edo State, Nigeria
}

\section{*AVENBUAN, N; ALILE, OM; IDUSERI, OM}

\author{
University of Benin, Benin City, Edo State, Nigeria \\ *Corresponding Author Email: Avenbuannosayaba@yahoo.com
}

\begin{abstract}
The geophysical study of the spread of plant roots have become imperative due to its effect on buildings. Most buildings constructed close to trees; without taking into consideration the extent of root spread, have experienced cracks which sometimes lead to the collapse of such buildings. To investigate the horizontal and vertical spread of plant roots at the University of Benin Engineering field, Edo State, Nigeria, a two-dimensional electrical resistivity imaging was done using the Wenner-Schlumberger array configuration. Data were collected along two profiles; profile 1 was taken along tree paths and profile 2 along grassland area, some distance from profile 1. Profile 1 showed a very resistive top layer underlain by a low resistive layer. The top layer which appeared to be highly resistive was due to the presence of fluid absorbers within that layer. The fluid absorbers are the roots from the trees which are distributed both vertically and horizontally within the layer. With the inversion results, the depths of the roots were estimated to be between $5.00 \mathrm{~m}$ and $7.50 \mathrm{~m}$ from the surface; with resistivity values of between $610.00 \Omega \mathrm{m}$ to $1700 \Omega \mathrm{m}$. The resistivity distribution obtained in profile 2 appears to be more homogeneous than the results obtained from profile 1 with resistivity values of between $320 \Omega \mathrm{m}$ to $3500.00 \Omega \mathrm{m}$ from the top layer to the bottom layer. The uniformity in the resistivity distribution with depth was due to the absence of tree roots within the formation.
\end{abstract}

\section{DOI: https://dx.doi.org/10.4314/jasem.v24i11.4}

Copyright: Copyright $(0) 2020$ Avenbuan et al. This is an open access article distributed under the Creative Commons Attribution License (CCL), which permits unrestricted use, distribution, and reproduction in any medium, provided the original work is properly cited.

Dates: Received: 22 September 2020; Revised: 29 October 2020; Accepted: 04 November 2020

Keywords: Tree roots, inhomogeneous, resistivity

The damage on structures caused by tree roots can be direct or indirect. Direct damage is damage caused by the mechanical action of any part of a tree in direct contact with part of a structure. Roots encountering a solid object will divert and follow the course of least resistance, thereby causing no damage. The continuous radial expansion of trunks and structural roots in contact with a structure and in a restricted space, however, may exert sufficient pressure to displace heavy structures (Biddle, 1998b). Indirect damage is caused by the influence of a tree on soil moisture levels of a substrate prone to shrinkage and expansion. The ground is de-hydrated through the transpiration of leaves abstracting moisture from the ground and, less significantly, by the interception of rainfall by the crown. The ground contracts and this can lead to crack in buildings or make foundations unstable. A thorough near-surface investigation and characterization prior to building construction is an essential component of foundation design to ensure safety of human lives and properties; where there are inadequate or inefficient subsoil characterization and soil strength determination, a potential foundationrelated failures or structural dilapidations may result (Oyeyemi et al., 2017). Detailed geological investigation is necessary where there are heterogeneities and variations in the subsurface earth due to the presence of tree roots in order to ascertain the extent of the root spread. Usually winter rainfall results in full recovery so that the process is seasonal. On the other hand, removal of a tree results in longterm recovery and expansion of the ground (Biddle, 1998b). According to Ward (1953), the influence of tree roots on the stability of shallow foundations can be reduced (or avoided) using the proximity rule, which suggests that the distance, $D$, between a shallow foundation and a tree must be equal to or greater than the height $H$ of the tree (i.e. $D / H \geq 1$ ). All species of trees are categorized as, 'high', 'moderate' or 'low' water demanders. Species in the high group are generally considered to extend their influence on soil moisture levels over a distance of 125 percent the height of the tree. Moderate water demanders extend their influence over 75 percent of their height and low water demanders extend their influence over 50 per cent of their height. Several other nonempirical rules have recommended distances for planting trees based on their maximum expected heights at maturity to avoid the differential settlements. However, these rules cannot be extended to all types of soils and regions around the world (Areghan et al., 2015). Growing roots change soil structure, displace pore 
water and gas and increase porosity. Plant water balance and physiological processes depend on the control of root water uptake (Anderegg and HilleRisLambers, 2016). There are significant gaps in resolution and sampling volume between common approaches to monitor root-zone moisture. Remote sensing provides regional-scale estimates of water content, but has limited spatial and temporal resolution and marginal depth penetration (Scott et al., 2003). In contrast, time domain reflectometry and other probes provide accurate point-scale estimates of soil moisture with high temporal resolution, but cannot readily be up-scaled (Robock et al., 2000). In addition, remote sensing and point-based methods provide only limited information about moisture percolation below the root zone, and thus groundwater recharge rates that are essential for water resources management. With surface geophysical methods, such as electrical resistivity imaging (ERI), it is possible to monitor water content at soil-bedrock depths between 2.50 and $17.00 \mathrm{~m}$ and at frequent time intervals (Beff et al., 2013). ERI is a nondestructive, geoelectrical method to examine soil properties (Martinez-Pagan et al., 2013); it allows the generation of two- and/or threedimensional images and maps depicting both the spatial and temporal variation in soil electrical resistivity, corresponding to variations in soil water content (Cosentini et al., 2012), and singularities like cracks and fractures. The resistivity of rocks and soil may vary depending on their water content, water salinity and mode of pore distribution, with a wide range of values $\left(1-10^{9} \Omega \mathrm{m}^{-1}\right)$; lower values indicate higher water content and vice versa. ERI finds application in the study of inhomogeneous medium (Aigbogun et al., 2017), the determination of contaminants in environmental study (Olaseni et al., 2018), the determination of mineral deposit within the subsurface (Ogunlana et al., 2019) and the study of archaeological sites (Papadopoulos et al., 2006). The ground resistivity is related to various geological parameters such as the mineral and fluid content, porosity and degree of water saturation in the rock. Although ERI has been used to characterize temporal changes in moisture content (Jayawickreme et al., 2008) explore for the first-time natural interactions between seasonal soil moisture dynamics, climate variability, and vegetation differences using timelapse ERI. For this analysis, they equipped a forestgrassland ecotone with a suite of hydrogeophysical equipment. Their observations from this ecotone demonstrate that ERI can be used to accurately quantify the spatiotemporal distribution of root-zone moisture content, bridging critical gaps between remotely-sensed and in-situ point measurements. This information is essential to project the influence of changing climate and land covers on hydrologic fluxes and ecosystem sustainability. The purpose of this research is to investigate the depth and spread of plant roots due to its effects on buildings.

\section{MATERIALS AND METHOD}

The study location, the University of Benin Engineering Field, is located in Ugbowo area of Edo State, and lies within latitude $6^{\circ} 24^{\prime} 06^{\prime \prime} \mathrm{N}$ and $6^{\circ} 24^{\prime} 12^{\prime \prime}$ $\mathrm{N}$ and longitude $5^{\circ} 36^{\prime} 44^{\prime \prime} \mathrm{E}$ and $5^{\circ} 36^{\prime} 51^{\prime \prime} \mathrm{E}$. It is underlain by sedimentary formation of the South Sedimentary Basin. The formation is characterized by top reddish to reddish brown lateritic massive fairly indurate clay and sand. This is often marked with reticulate muderacks. This caps the underlying more friable pinkish-yellowish white often gravelly-pebble sands clayey soils, sands and clay (Akujieze, 2004).

In order to study the effect of tree roots on electrical resistivity of the subsurface lithology in the study location, data were obtained along two profile lines; Profile 1 was taken along the path dominated by trees and profile 2 was along a grassland area; some distance from the tree area. A direction of W-E azimuth was adopted for the two profiles as shown in Figure 1.

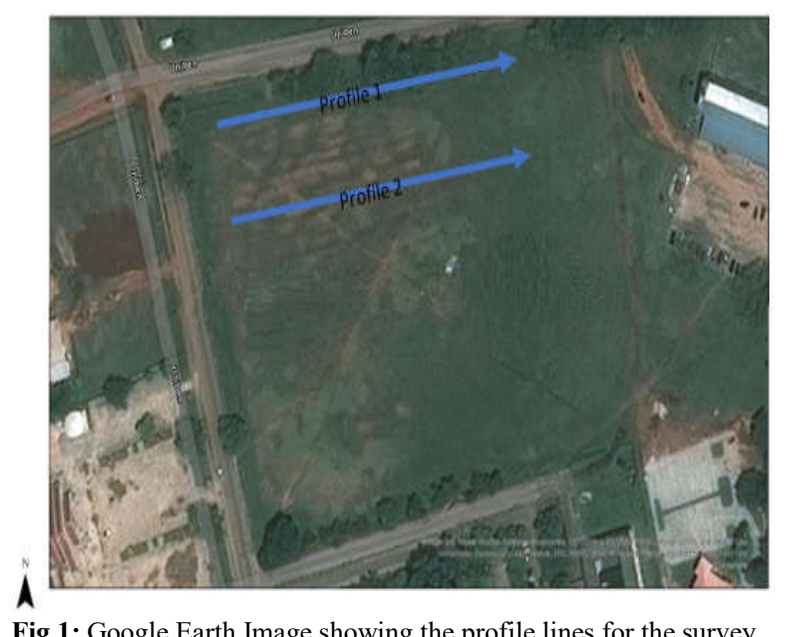

Fig 1: Google Earth Image showing the profile lines for the survey location

The materials used for data acquisition include; the PASI Terrameter, battery, twenty-one (21) stainless steel electrodes, four (4) electrode connectors or clips, cables and reels, hammers, generating set, extension boxes, measuring tapes, GPS device, notebook, pen and umbrella.

Field Theory: The fundamental physical law used in resistivity surveys is Ohm's law; a law that governs the flow of current in the ground. It should be noted that Ohm's law applies in the vast majority of geophysical cases unless high current densities occur, in which case the linearity of the law may break down. 
The resistance offered by the subsurface geologic feature is obtained by calculation using:

$$
R=\frac{\Delta V}{I} \quad 1
$$

Where; $\Delta V$ is the electric potential difference across the potential electrodes; $\mathrm{M}$ and $\mathrm{N}, I$ is the current introduced into the subsurface using a pair of current electrodes; A and B.

The data collection was done using WennerSchlumberger array configuration (Figure 2). The choice of the configuration is largely because of its good signal-to-noise ratio and better horizontal coverage. The maximum depth of penetration of this array is greater than the Wenner array configuration (Loke, 2000). In this configuration, electric current is introduced into the subsurface using a pair of current electrodes; A and B. This current creates an electric field within the subsurface. The electric potential distribution due to this injected current is measured across a pair of potential electrodes; $\mathrm{M}$ and $\mathrm{N}$.

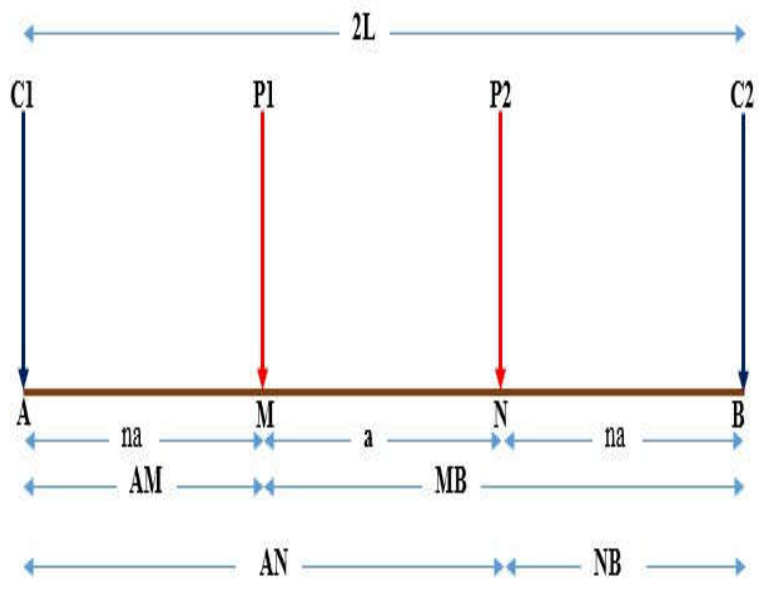

Fig 2: Electrode configuration adopted for the survey

The $\mathbf{n}$ factor is the ratio of the separation between the first current electrode; $\mathrm{C} 1$, and the first potential electrode; P1, or the second current electrode; C2, and the second potential electrode; P2, to the separation between the potential electrode pair. The potentials at the electrodes $\mathrm{M}$ and $\mathrm{N}$ are

$$
V_{M}=\frac{\rho I}{2 \pi}\left[\frac{1}{A M}-\frac{1}{M B}\right] \text { and } V_{N}=\frac{\rho I}{2 \pi}\left[\frac{1}{A N}-\frac{1}{N B}\right] \quad 2
$$

The potential difference, $\left(\Delta \mathrm{V}_{\mathrm{MN}}=\mathrm{V}_{\mathrm{M}}-\mathrm{V}_{\mathrm{N}}\right)$, between the two potential electrodes is given as

$$
\Delta V_{M N}=V_{M}-V_{N}=\frac{\rho I}{2 \pi}\left\{\left[\frac{1}{A M}-\frac{1}{M B}\right]-\left[\frac{1}{A N}-\frac{1}{N B}\right]\right\}=\frac{\rho I}{2 \pi}\left\{\frac{1}{A M}-\frac{1}{M B}+\frac{1}{N B}-\frac{1}{A N}\right\} \quad 3
$$

The resistivity, $\rho$, is obtained by rearranging Equation 3, and is given as

$$
\begin{gathered}
\rho=\frac{2 \pi \Delta V_{M N}}{I}\left\{\frac{1}{A M}-\frac{1}{M B}+\frac{1}{N B}-\frac{1}{A N}\right\}^{-1} 4 \\
\rho=K R \quad 5
\end{gathered}
$$

Where $K=2 \pi\left\{\frac{1}{A M}-\frac{1}{M B}+\frac{1}{N B}-\frac{1}{A N}\right\}^{-1}$ and $R=\frac{\Delta V_{M N}}{I}$

For this array type, the geometric factor; $\mathrm{K}$ is given as

$$
K=2 \pi\left\{\frac{1}{A M}-\frac{1}{M B}+\frac{1}{N B}-\frac{1}{A N}\right\}^{-1}=\pi\left(\frac{L^{2}}{a}-\frac{a}{4}\right)
$$

Where: $\mathbf{a}=$ the separation between the potential electrode pair $(\mathbf{a}=\mathrm{MN})$; and $\mathrm{L}$ is the average separation between the current electrode pair; $\mathrm{A}$ and $\mathrm{B}(\mathrm{L}=\mathrm{AB} / 2)$.

The general expression for the geometric factor, $\mathrm{K}$ is

$$
K=\pi n(n+1) a \quad 7
$$

The electrodes were arranged along the profile lines which were $200 \mathrm{~m}$ long each with a minimum electrode spacing of $10 \mathrm{~m}$. Starting from the origin, the output terminals of the current cables were connected to electrodes 1 and 4 with the aid of electrode connectors or clips and the input terminals of the potential cables were connected to electrodes 2 and 3. The input terminals of the current cables and the output terminals of the potential cables were connected to the Terrameter. The cables are moved along each profile line; keeping the $10.00 \mathrm{~m}$ electrode spacing constant for the first traverse. After the first traverse, the first current and potential electrodes as well as the second current and potential electrodes are kept $20.00 \mathrm{~m}$ apart 
while the separation between the potential electrodes is kept constant at $10.00 \mathrm{~m}$. This implies that the current cables were connected to the first and sixth electrodes while the potential cables were connected to the third and fourth electrodes along the profile lines before the second traverse was taken. Figure 3 shows the electrode separation for the different traverses along the profile.

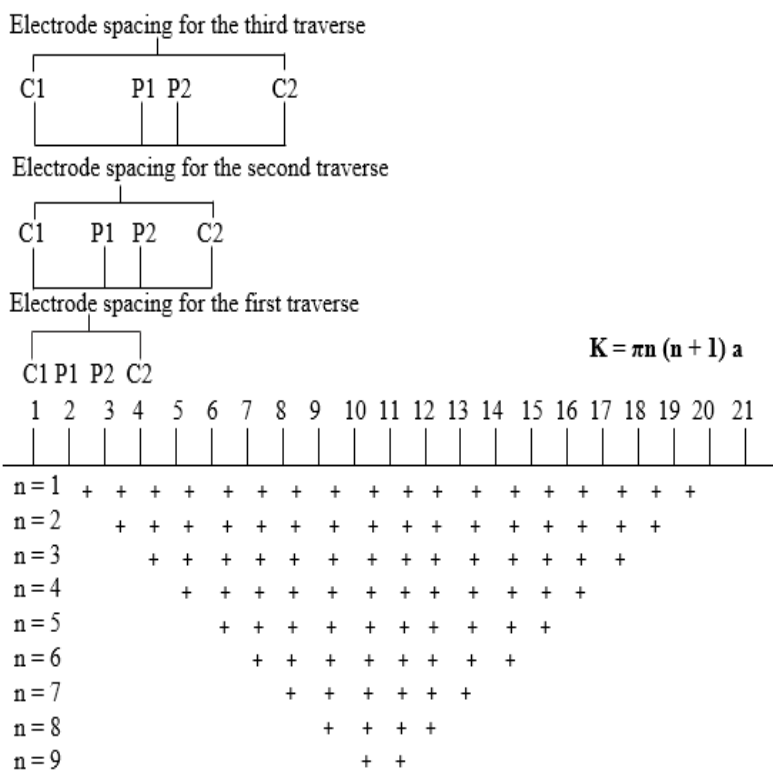

Fig 3: Current and potential electrode separations for each traverse

\section{RESULTS AND DISCUSSION}

Figure 4a showed a very resistive top layer underlain by a low resistive layer. The resistive top layer with resistivity values of between $610.00 \Omega \mathrm{m}$ to $1,700.00 \Omega \mathrm{m}$ was between $5.00 \mathrm{~m}$ and $7.50 \mathrm{~m}$ thick. The low resistive layer which was directly below the high resistive layer has resistivity values of between $160.00 \Omega \mathrm{m}$ to $400.00 \Omega \mathrm{m}$ with thickness of between $13.56 \mathrm{~m}$ and $16.06 \mathrm{~m}$ at a horizontal distance of between $27.31 \mathrm{~m}$ to $108.46 \mathrm{~m}$ and thickness of between $24.40 \mathrm{~m}$ to $26.90 \mathrm{~m}$ at a horizontal distance of between $130.00 \mathrm{~m}$ to $200.00 \mathrm{~m}$. The low resistive layer was partitioned by a resistive subsurface feature projecting from the bottom to the top of the inversion model and has resistivity values of between $1132.00 \Omega \mathrm{m}$ to $3500.00 \Omega \mathrm{m}$. Figure $4 \mathrm{~b}$ showed a fairly resistive inhomogeneous zone to maximum depth of about $20.63 \mathrm{~m}$ with resistivity values of between $320 \Omega \mathrm{m}$ to $1113 \Omega \mathrm{m}$ and to depths of between $9.27 \mathrm{~m}$ and 20.63 $\mathrm{m}$. Below the inhomogeneous zone are layers that are homogeneous with varying thickness and the resistivity values are between $1113 \Omega \mathrm{m}$ to $3500 \Omega \mathrm{m}$. In Figure 4a, the subsurface resistivity within the tree region to a depth of between $5.00 \mathrm{~m}$ and $7.50 \mathrm{~m}$ from the surface appeared to be high due to the presence of fluid absorbers within that depth. The resistivity values to these depths were between $610.00 \Omega \mathrm{m}$ to $1,700.00 \Omega \mathrm{m}$. The absorbers were the roots from the trees which were distributed both vertically and horizontally within the layer.

(a)
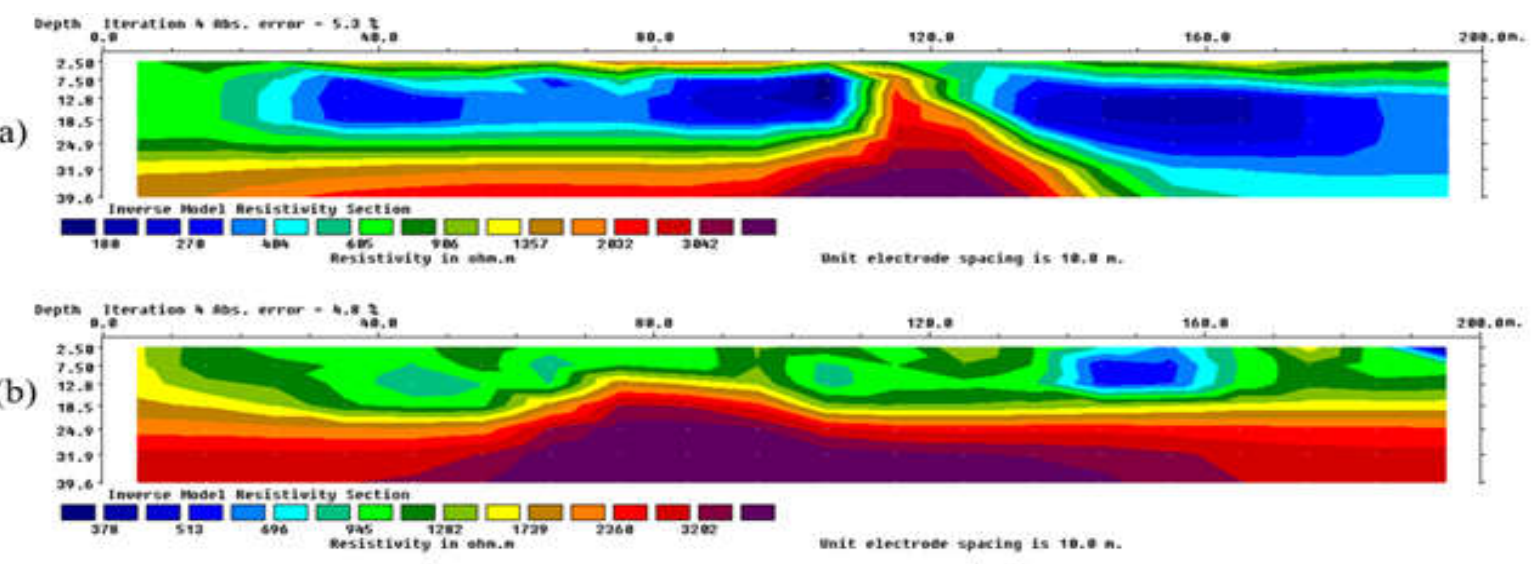

Figure 4: Result of the 2D inversion for the (a) first profile (b) second profile

The roots absorbed the fluid content within the subsurface, thereby resulting in the dryness of the layer where these roots were located and also increase in the resistivity distribution within the layer. The high resistivity values measured indicates the absorption rate of the roots. The plant roots also interfered with the electric flux distribution within the subsurface. This interference led to a reduction in the electric current that passed through the tree roots; which made the formation to be resistive. Directly below this high resistive zone was an inhomogeneous, high moisture content saturated zone with resistivity of between $160.00 \Omega \mathrm{m}$ to $400.00 \Omega \mathrm{m}$ and thickness of between $13.56 \mathrm{~m}$ and $26.90 \mathrm{~m}$. Below the high moisture content layer were homogeneous layers with varying resistivity values of between $605.00 \Omega$ m to 3500.00 $\Omega \mathrm{m}$. The resistivity distribution in the $2 \mathrm{D}$ inversion model in Figure $4 \mathrm{~b}$ appeared to be more homogeneous 
when compared to the resistivity model in Figure 4a. Figure $4 \mathrm{~b}$ showed a very resistive model with the lowest resistivity value of about $320 \Omega \mathrm{m}$ and a maximum resistivity of $3500.00 \Omega \mathrm{m}$. The resistivity values of the layers increased from top to bottom.

Conclusion: The top layer in profile 1 appeared to be highly resistive (up to about $1700 \Omega \mathrm{m}$ ) to depths of between $5.00 \mathrm{~m}$ and $7.50 \mathrm{~m}$. This was followed by low resistive layer. The model obtained from profile 2 showed resistivity values of between $320 \Omega \mathrm{m}$ and $1113 \Omega \mathrm{m}$ within the top layer. The resistivity values increased with depth unlike what was obtained in profile 1 . We therefore concluded that the high resistive top layer which was followed by low resistive layer in profile 1 was largely due to the presence of fluid absorbers (plant roots). Hence, the twodimensional ERI can therefore be used to investigate the extent of the horizontal spread and depth of tree roots within the study location.

\section{REFERENCES}

Aigbogun, CO; Alile, OM; Egbai, JC (2017).

Geoelectrical Imaging for Shallow Site Investigation at Ekiugbo in Uhunmwode Local Government Area of Edo State, Nigeria. J. Appl. Sci. Environ. Manage. 21 (5): 873-876.

Akujieze, CN (2004). Effects of Anthropogenic Activities (Sand Quarrying and Waste Disposal) on Urban Groundwater System and Aquifer Vulnerability Assessment in Benin City, Edo State, Nigeria. PhD Thesis, University of Benin, Benin City, Nigeria.

Anderegg, LD; HilleRisLambers, J (2016). Drought stress limits the geographic ranges of two tree species via different physiological mechanisms. Glob. Change Biol. 22: 1029-1045.

Areghan, J; Vanapalli, SK; Oh, WT; Bo, MW (2015). Settlement behaviour of a soil due to artificial tree roots. Environmental Geotechnics. 2 (1): 18-25.

Beff, L; Günther, T; Vandoorne, B; Couvreur, V; Javaux, M; (2013). Three-dimensional monitoring of soil water content in a maize field using Electrical Resistivity Tomography. Hydrol. Earth Syst. Sci. 17: 595-609.

Biddle, PG (1998b). Tree Root Damage to Buildings. Volume 2 Patterns of Soil Drying in Proximity to Trees on Clay Soils. Willowmead Publishing Ltd., Wantage UK.

Cosentini, RM; Della Vecchia, G; Foti, S; Musso, G; (2012). Estimation of the hydraulic parameters of unsaturated samples by electrical resistivity tomography. Geotechnique. 62: 583-594.

Jayawickreme, DH; Van Dam, RL; Hyndman, DW (2008). Subsurface imaging of vegetation, climate, and root-zone moisture interactions. Geophys. Res. Lett., 35, L18404.

Loke, MH (2000). Electrical imaging surveys for environmental and engineering studies: A practical guide to 2-D and 3-D surveys. http://www.terrajp.co.jp/lokenote.pdf.

Martinez-Pagan, P; Gomez-Ortiz, D; Martin-Crespo, T; Manteca, JI; Rosique, M; (2013). The electrical resistivity tomography method in the detection of shallow mining cavities. A case study on the Victoria Cave, Cartagena (SE Spain). Eng. Geol. 156: 1-10.

Ogunlana, OF; Alile, OM; Airen, OJ; (2019). Twodimensional Electrical Resistivity Tomography of Bitumen Occurrence in Agbabu, Southwest Nigeria. Current Journal of Applied Science and Technology. 36(1): 1-9.

Olaseni, VB; Onifade, YS; Airen, JO; Alile, OM; (2018). Geoelectrical Subsurface Imaging for the Mapping of Leachate and Contaminant Plume around Septic Tanks Within the Staff Quarters in University of Benin, Benin City, Nigeria. Asian J. Phy. Chem. Sci. 5(4): 1-10, 2018.

Oyeyemi, KD; Aizebeokhai, AP; Adagunodo, TA; Olofinnade, OM; Sanuade, OA; Olaojo, AA (2017). Subsoil characterization using geoelectrical and geotechnical investigations: implications for foundation studies. Inter. J. Civil Engineer. Tech. 8 (10): 302-314.

Papadopoulos, NG; Tsourlos, P; Tsokas, GN; Sarris, A (2006). Two-dimensional and Three-dimensional Resistivity Imaging in Archaeological Site Investigation. Archaeol. Prospect. 13: 163-181

Robock, A; Vinnikov, KY; Srinivasan, G; Entin, JK; Hollinger, S. E; Speranskaya, NA; Liu, SX; Namkhai, A (2000). The global soil moisture data bank, Bull. Am. Meteorol. Soc. 81: 1281- 1299.

Scott, CA; Bastiaanssen, WGM; Ahmad, MUD (2003). Mapping root zone soil moisture using remotely sensed optical imagery. J. Irrig. Drain. Eng. 129: 326-335.

Ward, WH (1953). Soil movements and weather. In Proceeding of the 3rd International Conference Soil Mechanics, Zurich, vol. 2, Organizing Committee ICOSOMEF, pp. 477-481. 